\title{
PENGARUH KECEMASAN BELAJAR MATEMATIKA, PERSEPSI SISWA TENTANG KETERAMPILAN MENGAJAR GURU, DAN IKLIM KELAS TERHADAP HASIL BELAJAR MATEMATIKA MELALUI MOTIVASI BELAJAR PADA SISWA KELAS VIII SMP NEGERI DI TANA TORAJA
}

\author{
THE INFLUENCE OF ANXIETY IN LEARNING MATHEMATICS, STUDENTS \\ PERCEPTION ON TEACHER'S TEACHING SKILLS, AND CLASSROOM CLIMATE ON \\ LEARNING OUTCOMES IN MATHEMATICS THROUGH LEARNING MOTIVATION OF \\ CLASS VIII STUDENTS AT SMPN IN TANA TORAJA
}

\author{
Suarti Djafar \\ Program Studi Pendidikan Matematika, STKIP Muhammadiyah Enrekang, Indonesia \\ Email: suartidjafar@gmail.com
}

\begin{abstract}
The study aims at investigating the description and the influence of learning anxiety, students' perceptions on teacher's teaching skills, classroom climate, and learning motivation on learning outcomes of Mathematics. The study is an ex post facto with causality. The sample were 239 students of class VIII selected by employing proportional stratified random sampling. Data were collected using several instruments : (1) questionnaire of learning anxiety, (2) questionnaire of students' perception on teacher's teaching skills, (3) questionnaire of classroom climate, (4) questionnaire of learning motivation, and (5) test of learning outcomes. Data were analyzed using descriptive statistics and inferential statistics with SEM method. The results of the study reveal that (1) class VIII students at SMP in Tana Toraja have medium learning anxiety, students' perception on teacher's teaching skills is in high category, the classroom climate is in high category, learning motivation is in high category, and learning outcomes is in medium category, (2) the learning anxiety gives positive and significant influence $(p=0,379)$ on learning outcomes, (3) students' perception on teacher's teaching skills give positive and significant influence ( $p=$ $0,473)$ on learning outcomes, (4) classroom climate gives negative and significant influence $(p=0,519)$ on learning outcomes, (5) learning anxiety gives positive but insignificant $(p=0,9317)$ on learning outcomes through learning motivation, (6) students' perception on teacher's teaching skills give positive and significant influence $(p=0,9447)$ on learning outcomes through learning motivation of students, (7) classroom climate gives negative and insignificant influence $((p=0,9015)$ on learning outcomes through learning motivation of students.
\end{abstract}

Keywords: Learning Anxiety, Students' Perceptions, Classroom Climate, Learning Motivation, Struktural Equation Modeling (SEM)

Abstrak. Masalah yang menjadi fokus dalam penelitian ini adalah faktor-faktor yang dapat mempengaruhi hasil belajar siswa sebagai output dari proses pembelajaran yang dijadikan sebagai cerminan utama mutu pendidikan dari suatu sekolah. Penelitian ini bertujuan untuk mengetahui gambaran dan pengaruh kecemasan belajar, persepsi siswa tentang keterampilan

Suarti Djafar. (2018). Pengaruh Kecemasan Belajar Matematika, Persepsi Siswa Tentang Keterampilan Mengajar Guru, Dan Iklim Kelas Terhadap Hasil Belajar Matematika Melalui Motivasi Belajar Pada Siswa Kelas Viii Smp Negeri Di Tana Toraja. Edumaspul - Jurnal Pendidikan, 2(1), 11-23. 
mengajar guru, iklim kelas, dan motivasi belajar terhadap hasil belajar matematika. Jenis penelitian ini adalah expost-facto yang bersifat kausalitas. Sampel penelitian sebanyak 239 yang dipilih dari siswa-siswa kelas VIII SMP di Kabupaten Tana Toraja dengan menggunakan teknik penyampelan proporsional stratified random sampling. Teknik pengumpulan data dengan menggunakan instrumen: (1) angket kecemasan belajar, (2) angket persepsi siswa tentang keterampilan mengajar guru, (3) angket iklim kelas, (4) angket motivasi belajar, (5) tes hasil belajar. Data dianalisis dengan statistika deskriptif dan statistika inferensial dengan metode SEM.Hasil penelitian menunjukkan bahwa: (1) Siswa kelas VIII SMP di Kabupaten Tana Toraja memiliki kecemasan belajar pada kategori sedang, persepsi siswa tentang keterampilan mengajar guru pada kategori tinggi, iklim kelas pada kategori tinggi, motivasi belajar pada kategori tinggi, dan hasil belajar siswa pada kategori sedang, (2) kecemasan belajar berpengaruh positif dan signifikan $(r=0,193)$ terhadap hasil belajar, (3) persepsi siswa tentang keterampilan mengajar guru berpengaruh positif dan tidak signifikan $(r=0,070)$ terhadap hasil belajar, (4) iklim kelas berpengaruh positif dan tidak signifikan $(\mathrm{r}=0,024)$ terhadap hasil belajar, $(5)$ kecemasan belajar berpengaruh positif dan tidak signifikan $(\mathrm{r}=0,009)$ terhadap hasil belajar melalui motivasi belajar, (6) persepsi siswa tentang keterampilan mengajar guru berpengaruh negatif dan tidak signifikan $(\mathrm{r}=-0,009)$ terhadap hasil belajar melalui motivasi belajar, (7) iklim kelas berpengaruh positif dan tidak signifikan $(r=0,103)$ terhadap hasil belajar melalui motivasi belajar siswa.

Kata Kunci. Kecemasan Belajar, Persepsi Siswa, Iklim Kelas, Motivasi Belajar, Struktural Equation Modeling (SEM)

\section{PENDAHULUAN}

Dalam keseluruhan proses pendidikan di sekolah, kegiatan belajar merupakan kegiatan yang paling pokok. Hal ini berarti bahwa berhasil tidaknya pencapaian tujuan pendidikan sebagaimana yang tertuang dalam Undang-undang Republik Indonesia No. 20 tahun 2003 tentang sistem pendidikan nasional yaitu "Untuk berkembangnya potensi peserta didik agar menjadi manusia yang beriman dan bertakwa kepada Tuhan Yang Maha Esa, berakhlak mulia, sehat, berilmu, cakap, kreatif, mandiri, dan menjadi warga negara yang demokratis serta bertanggung jawab" sangat tergantung pada bagaimana proses belajar yang dialami oleh siswa sebagai peserta didik.

Matematika merupakan salah satu bidang studi yang menduduki peranan penting yang diajarkan bukan hanya untuk mengetahui dan memahami apa yang terkandung dalam matematika itu sendiri, tetapi juga untuk melatih pola pikir siswa agar dapat memecahkan masalah dengan kritis, logis, dan tepat. Hal ini sesuai dengan tujuan pembelajaran matematika di sekolah yaitu memberikan tekanan pada penataan nalar, pembentukan sikap siswa dalam menerapkan matematika.

Kualitas pengajaran matematika dapat dilihat dari tinggi rendahnya hasil belajar matematika siswa. Hasil belajar matematika siswa tidak lepas dari bagaimana siswa mengalami proses belajar yang pada dasarnya merupakan proses perubahan tingkah laku untuk mencapai tujuan tertentu. Perbedaan hasil belajar matematika siswa di sekolah dipengaruhi oleh banyak faktor. Menurut Slameto (2010 : 34) faktor-faktor yang mempengaruhi belajar banyak jenisnya tetapi dapat digolongkan menjadi dua golongan saja, yaitu faktor intern dan faktor ekstern. Faktor intern adalah semua yang berasal dari dalam diri siswa, seperti minat, kecemasan belajar, motivasi belajar, persepsi dan lain sebagainya. Sedangkan faktor ekstern adalah semua faktor yang berasal dari luar diri siswa, seperti iklim sekolah, kondisi lingkungan di sekitar siswa, iklim kelas, keterampilan mengajar, lain sebagainya. 
Elliot (1996 : 342) menyebutkan bahwa pada dasarnya kecemasan dalam tingkat yang rendah dan sedang berpengaruh positif terhadap penampilan belajar siswa, salah satunya dapat meningkatkan motivasi belajar, sedangkan kecemasan siswa pada taraf yang tinggi dapat mengganggu dan memperburuk perilaku belajar siswa.

Selanjutnya menurut Dimyati dan Mudjiono, untuk memperoleh hasil belajar yang baik dibutuhkan suatu dorongan yang merupakan kekuatan mental untuk melakukan kegiatan dalam rangka memenuhi harapan. Dorongan yang berorientasi pada tujuan tersebut merupakan inti motivasi (Dimyati \& Mudjiono, 2006 : 81). Sedangkan Slavin (dalam Baharuddin, 2007: 22) mengemukakan bahwa motivasi adalah salah satu faktor yang mempengaruhi keefektivan kegiatan belajar siswa. Motivasilah yang mendorong siswa ingin melakukan kegiatan belajar.

Usaha untuk meningkatkan hasil belajar siswa selain dipengaruhi oleh hal-hal di atas, yang tidak kalah penting adalah adalah persepsi siswa. Persepsi siswa yang dimaksud adalah persepsi siswa mengenai keterampilan mengajar guru. Adeogun (dalam Olayeye, 2011: 505) berpendapat bahwa kualitas dari sistem pendidikan tergantung dari kualitas tenaga pengajar dan sebuah sekolah tanpa sumber daya mustahil dapat mencapai tujuan dan sasaran system pendidikan.

Menurut Suparman (2010 : 61), banyak orang pintar dan berilmu akan tetapi tidak mampu menyampaikan ilmunya, apalagi untuk mentransfer ilmunya kepada orang lain. Sedangkan guru dikaruniai dua kemampuan, yaitu menyampaikan ilmu dan mentransfer ilmu. Hanya saja proses penyampaian dan transferisasi ilmu tidak akan berhasil dengan baik jika tidak ada metode atau gaya mengajar yang jelas, terarah, memiliki tujuan, dan sistematis. Oleh karena itu, pemakaian metode ataupun keterampilan dalam mengajar sangat diperlukan agar proses penyampaian dan transferisasi ilmu dapat berjalan seperti yang diharapkan.

Salah satu faktor eksternal yang mempengaruhi hasil belajar siswa adalah iklim kelas. Lebih jauh Fraser (1986), mendokumentasikan lebih dari 45 penelitian yang membuktikan adanya hubungan yang positif antara iklim kelas dan hasil belajar siswa (dalam Tarmidi, 2006 : 9). Dalam kaitannya dengan pengaruh iklim kelas terhadap motivasi belajar, hasil penelitian yang dilakukan Juniman Silalahi menyatakan bahwa, terdapat pengaruh yang signifikan antara iklim kelas terhadap motivasi belajar. Di mana implikasinya adalah semakin rendah iklim kelas yang dibangun, maka rendah pula motivasi belajar yang ditampilkan oleh siswa. Demikian pula sebaliknya semakin tinggi iklim kelas dibangun maka semakin tinggi motivasi belajar yang ditampilkan.

Bertolak dari latar belakang di atas, peneliti tertarik untuk melakukan penelitian mengenai pengaruh kecemasan belajar matematika, persepsi siswa tentang keterampilan mengajar guru, iklim kelas, dan motivasi belajar terhadap hasil belajar matematika.

\section{METODE PENELITIAN}

\section{Jenis Penelitian}

Penelitian ini termasuk penelitian expost facto yang bersifat kausalitas. Penelitian ex-post facto disini dirancang untuk menerangkan adanya hubungan sebab akibat. Peneliti dalam hal ini akan menelusuri hubungan sebab akibat (kausal) dan menguji hipotesis yang telah dirumuskan sebelumnya antara lain: kecemasan belajar matematika, persepsi siswa tentang keterampilan mengajar guru, iklim kelas, dan motivasi belajar terhadap hasil belajar matematika. 


\section{Variabel Penelitian}

Variabel yang digunakan dalam penelitian ini ada tiga jenis, sesuai dengan karakteristik penelitian yang digunakan, yaitu variabel eksogen, intervening, dan endogen. Variabel eksogen dalam penelitian ini adalah kecemasan belajar matematika (X1), persepsi siswa tentang keterampilan mengajar guru (X2), dan iklim kelas (X3). Kemudian variabel intervening yaitu motivasi belajar (X4). Sedangkan variabel endogen dalam penelitian ini yaitu hasil belajar matematika (Y).

\section{Desain Penelitian}

Paradigma hubungan antar variabel

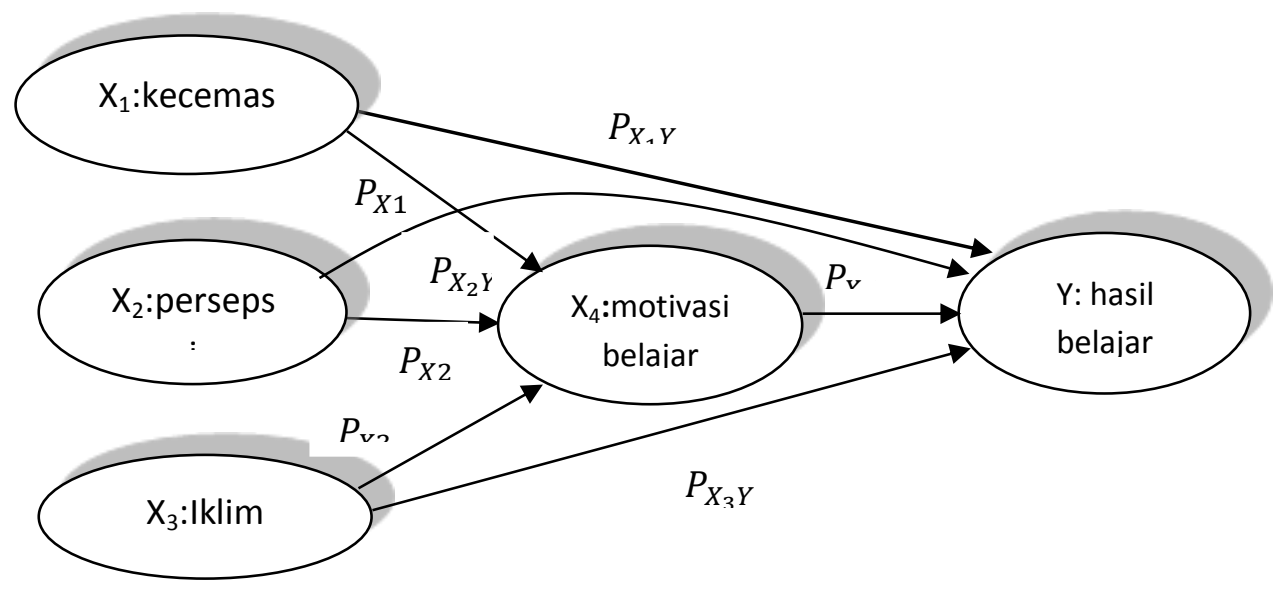

Berdasarkan gambar di atas maka dapat dibuat persamaan strukturalnya sebagai berikut:

1. $X_{4}=P_{41} X_{1}+P_{42} X_{2}+P_{43} X_{3}+z_{1}$

2. $Y=P_{y 1} X_{1}+P_{y 2} X_{2}+P_{y 3} X_{3}+P_{y 4} X_{4}+z_{2}$

\section{Populasi Dan Sampel}

a. Populasi

Populasi dalam penelitian ini yaitu seluruh siswa pada kelas VIII SMP Negeri di
Kabupaten Tana Toraja tahun ajaran 2013/2014. Berdasarkan data yang diperoleh dari Dinas Pendidikan Kabupaten Tana Toraja di peroleh jumlah SMP Negeri yang ada di Kabupaten Tana Toraja sebanyak 33 unit sekolah dengan jumlah keseluruhan siswa dari masing-masing sekolah tersebut khususnya kelas VIII adalah 3.025 siswa. 
b. Sampel

\begin{tabular}{ccccc}
\hline No. & Nama Sekolah & $\begin{array}{c}\text { Peringkat } \\
\text { Akreditasi }\end{array}$ & Kelas & $\begin{array}{c}\text { Jumlah } \\
\text { Sampel }\end{array}$ \\
\hline 1 & SMP N 1 Mengkendek & A & VIII $^{\mathrm{A}}$ & 27 \\
2 & SMP N 2 Makale & A & VIII $^{\mathrm{F}}$ & 23 \\
3 & SMP N 2 Saluputti & B & VIII $^{\mathrm{C}}$ & 26 \\
4 & SMP N 1 Bittuang & B & VIII $^{\mathrm{B}}$ & 32 \\
5 & SMP N 2 Rantetayo & B & VIII $^{\mathrm{D}}$ & 43 \\
6 & SMP N 4 Saluputti & B & VIII $^{\mathrm{A}}$ & 21 \\
7 & SMP N 5 Makale & $\mathrm{C}$ & VIII $^{\mathrm{A}}$, VIII $^{\mathrm{C}}$ & 40 \\
8 & SMP N 5 Mengkendek & - & VIII $^{\mathrm{A}}, \mathrm{VIII}^{\mathrm{B}}$ & 27 \\
\hline \multicolumn{7}{c}{ Total } & & 239 \\
\hline
\end{tabular}

Sampel Kelas (Kelompok) Dari Tiap Sekolah

\section{Instrumen Penelitian}

Pengumpulan data dilakukan dengan menggunakan instrumen yang berupa tes dan non tes. Untuk mengukur variabel hasil belajar matematika siswa, maka pengumpulan data yang dilakukan adalah dengan menggunakan tes. Tes adalah instrumen alat ukur yang dilakukan untuk pengumpulan data yang mana dalam memberikan respon atas pertanyaan dalam instrumen, peserta didik didorong untuk menunjukkan penampilan maksimal (Purwanto, 2011:63-64). Tes yang dimaksud dalam penelitian ini adalah tes hasil belajar (THB) dalam bentuk Pilihan Ganda yang dilakukan untuk mengukur sejauh mana kemampuan kognitif yang dapat dicapai oleh peserta didik.

Untuk mengukur kecemasan belajar matematika, persepsi siswa tentang keterampilan mengajar guru, iklim kelas, dan motivasi belajar maka pengumpulan data dilakukan dengan menggunakan non tes dalam bentuk skala. Menurut Azwar (2012:6) bahwa pengumpulan data yang dilakukan dengan menggunakan skala merupakan alat ukur atribut non-kognitif (psikologi) yang mengungkap indikator perilaku dari atribut tersebut. Alternatif jawaban pada skala kecemasan belajar matematika, persepsi siswa tentang keterampilan mengajar guru, dan motivasi belajar yang terdiri dari Sangat Sesuai (SS), Sesuai (S), Kurang Sesuai (KS) dan Tidak Sesuai (TS). Pemberian skor pada skala ini berkisar dari 1-4 berdasarkan item yang favorable dan unfavorable. Untuk item yang favorable jawaban $\mathrm{SS}=4, \mathrm{~S}=3$, $\mathrm{KS}=2, \mathrm{TS}=1$. Untuk item yang unfavorable jawaban $\mathrm{TS}=4, \mathrm{KS}=3, \mathrm{~S}=2$, dan $\mathrm{SS}=1$.

\section{Kriteria Pengklasifikasian Skor Variabel Penelitian}

Kategorisasi dilakukan untuk mengelompokkan subyek ke dalam kategori-kategori terpisah secara berjenjang. Untuk kriteria pengklasifikasian skor konstruk penelitian digunakan pengkategorian normatif skala pengukuran seperti pada tabel dibawah ini 
Kriteria Pengklasifikasian Skor Konstruk Penelitian

\begin{tabular}{cc}
\hline Interval Skor & Kriteria \\
\hline skor terendah $\leq$ skor $\leq \mu-1,5(\sigma)$ & Sangat Rendah \\
$\mu-1,5(\sigma)<$ skor $\leq \mu-0,5(\sigma)$ & Rendah \\
$\mu-0,5(\sigma)<$ skor $\leq \mu+0,5(\sigma)$ & Sedang \\
$\mu+0,5(\sigma)<$ skor $\leq \mu+1,5(\sigma)$ & Tinggi \\
$\mu+1,5(\sigma)<$ skor $\leq$ skor tertinggi & Sangat Tinggi \\
\hline
\end{tabular}

(Modifikasi dari Basori, 2013: 102)

Dimana: $\mu=$ Rerata skor hipotetik $=\frac{\text { skor terendah }+ \text { skor tertinggi }}{2}$

$$
\sigma=\text { Standar deviasi skor hipotetik }=\frac{\text { skor tertinggi-skor terendah }}{6}
$$

Pengkategorian variabel hasil belajar matematika siswa didasarkan pada departemen pendidikan ansional (Suherman, 2008 : 182), seperti pada tabel berikut.

\begin{tabular}{cc} 
Kriteria Pengklasifikasian & Skor Tes Hasil Belajar \\
\hline Interval Skor $(\%)$ & Kriteria \\
\hline $90 \leq$ skor $\leq 100$ & Sangat Tinggi \\
$75 \leq$ skor $<90$ & Tinggi \\
$55 \leq$ skor $<75$ & Sedang \\
$40 \leq$ skor $<55$ & Rendah \\
$0 \leq$ skor $<40$ & Sangat Rendah
\end{tabular}

\section{Teknik Analisis Data}

Keseluruhan data yang terkumpul melalui instrumen penelitian dianalisis dengan menggunakan statistik deskriptif dan juga statistik inferensial. Teknik analisis deskriptif yang digunakan untuk mendeskripsikan untuk mengetahui gambaran umum tentang variabel yang diteliti akan memperkuat analisis inferensial. Statistika deskriptif dimaksudkan untuk memberi gambaran alami data sampel dari variabel penelitian, diantaranya berupa rata-rata, standar deviasi, median, modus, standar deviasi, variansi, skewness, kurtosis, range, minimum, maksimum, dan analisis prosentase dengan menggunakan bantuan perangkat statistik SPSS 20.

Analisis statistik inferensial dilakukan dengan menggunakan Analisis Structural Equation Modeling (SEM) dengan bantuan perangkat statistik AMOS 20. Adapun uji asumsi yang harus dipenuhi 
dalam Analisis Structural Equation Modeling dalam Gozali (Nurhidayah, 2013 : 97) yaitu :

a. Uji data outlier

b. Uji normalitas data

c. Uji kesesuaian model (Goodness Of Fit Model)

Kesesuaian model dievaluasi melalui telaah terhadap berbagai kriteria goodness of fit.

d. Uji Signifikansi

Santoso (2012: 159) menjelaskan bahwa untuk kepraktisan, dalam AMOS uji signifikansi dapat langsung diketahui dengan mengamati kolom $p$ (probability). Namun untuk mengetahui signifikansi peranan secara tidak langsung maka diperlukan sobel test (Latan, 2013: 162). Ketentuan pengambilan keputusan adalah:

- Jika $p \geq \alpha$ (tarap signifikansi) maka $\mathrm{H}_{0}$ diterima .

- Jika $p<\alpha$ (tarap signifikansi) maka $\mathrm{H}_{0}$ ditolak (biasanya ditandai dengan bintang).

e. Respesifikasi Model

\section{HASIL PENELITIAN}

Pengujian hipotesis dalam penelitian ini menggunakan analisis jalur (Path Analysis). Hasil analisis yang

disajikan dalam Gambar 4.6 merupakan model persamaan struktural tahap awal yang dikembangkan

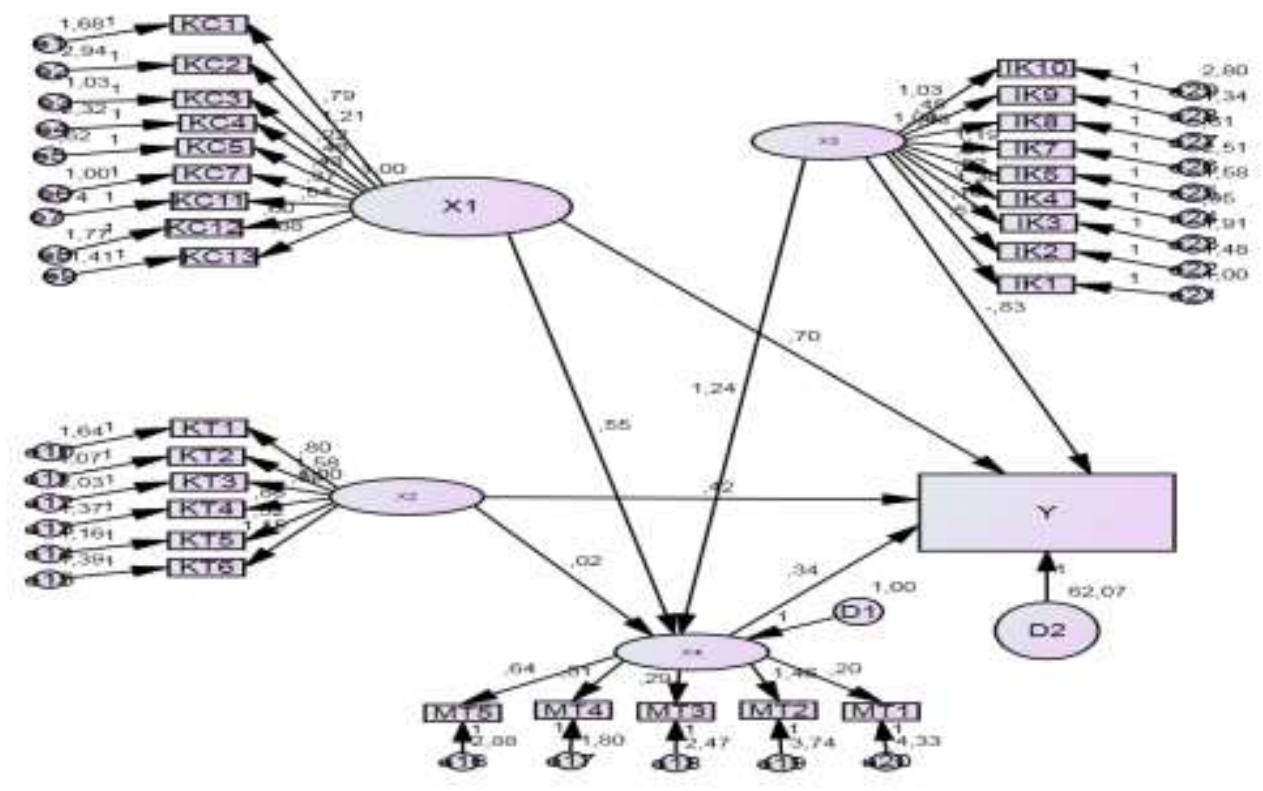

Gambar 4.6. Model persamaan struktural tahap awal 
Hasil estimasi melalui metode maksimum likelihood menghasilkan model yang belum dapat dijadikan patokan dalam estimasi parameter karena belum menunjukkan indeks overall fit yang memenuhi kriteria. Hal ini dapat dilihat melalui CMIN/DF, CFI, dan TLI yang kurang memberikan dukungan kecocokan model.

Model tahap awal masih memiliki indeks yang kurang cocok maka langkah berikutnya adalah meningkatkan indeks overall fit model tersebut. Pendekatan yang digunakan dalam meningkatkan indeks tersebut adalah pendekatan model building-trimming terhadap parameter melalui pertimbangan Modification Indices yang disediakan oleh AMOS 20.
Proses building-trimming dilakukan hingga diperoleh indeks overall fit yang lebih sesuai dan model tersebut kemudian dinyatakan sebagai model tahap final. Hasil analisis yang diperoleh, disajikan pada Gambar 4.7, yang menghasilkan indeks overall fit untuk model tahap akhir ini adalah nilai $\mathrm{p}=0,000<0,05, \mathrm{CMIN} / \mathrm{DF}=0,855<2$, RMSEA $=0,000<0,08, \mathrm{CFI}=1,000>0,90$, dan TLI $=1,046>0,90$. Dapat dilihat bahwa probabilitas masih belum memberikan nilai yang dapat diterima, sedangkan kriteria lainnya telah menunjukkan acceptable fit. Jadi telah memenuhi minimal 3 indeks untuk dapat dijadikan patokan kecocokan model. Dengan demikian model ini dapat diterima untuk analisis lebih lanjut.

Gambar 4.7 Model persamaan struktural tahap akhir

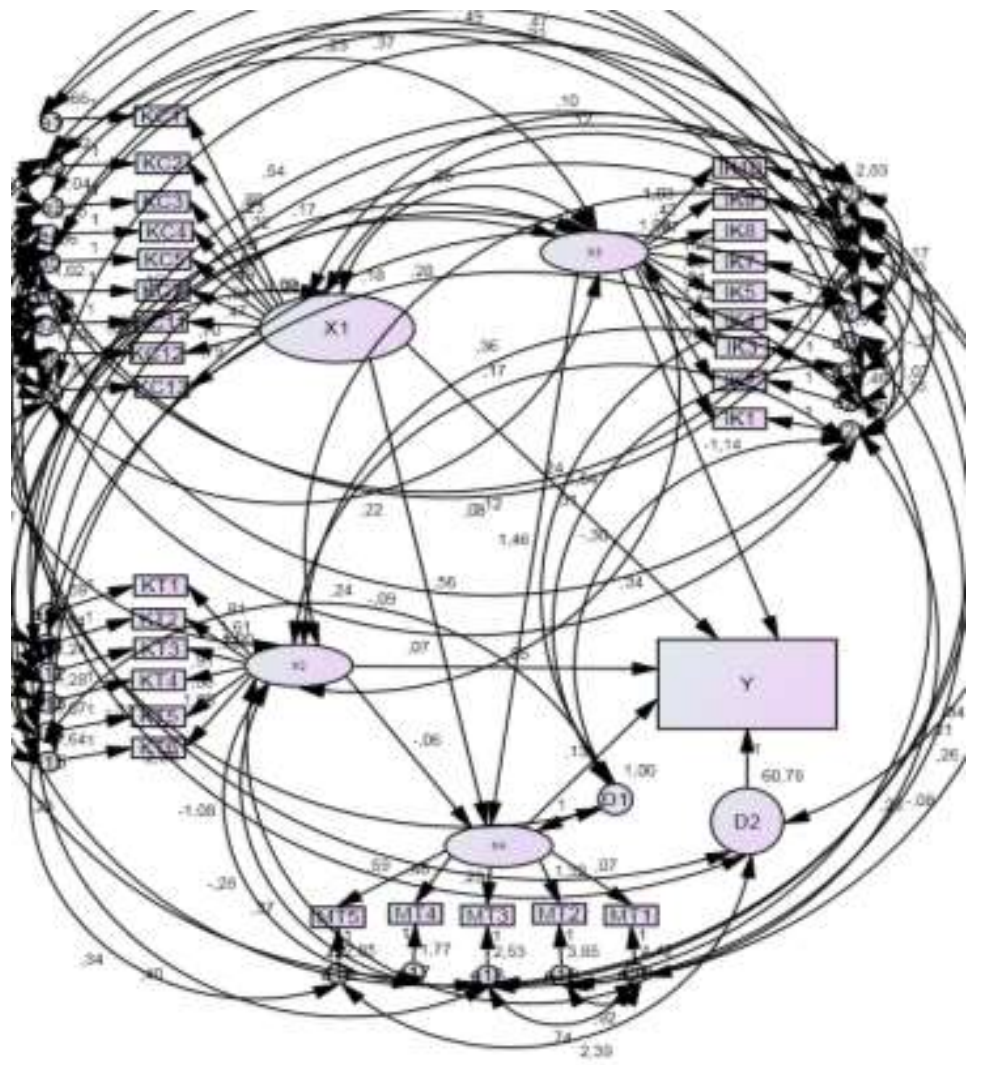


Keterangan:

$\longrightarrow=$ Hubungan Kausal

$\mathrm{X}_{1}=$ Kecemasan belajar $(\mathrm{KC})$

$\mathrm{X}_{2}=$ Persepsi siswa tentang keterampilan mengajar guru(KT)

$\mathrm{X}_{3}=$ Iklim Kelas (IK)

$\mathrm{X}_{4}=$ Motivasi Belajar $(\mathrm{KB})$

$\mathrm{Y}=$ Hasil belajar Matematika (HB)

Hasil estimasi parameter (regression weight) disajikan dalam Tabel 4.7 berikut:

Tabel 4.7. Regresion weights untuk model tahap akhir

\begin{tabular}{lll|rrrr}
\hline & & & Estimate & S.E. & C.R. & P \\
\hline X4 & $<---$ & X3 & 1,455 &, 358 & 4,066 &, 001 \\
X4 & $<---$ & X2 &,- 057 &, 150 &,- 383 &, 701 \\
X4 & $<---$ & X1 &, 560 &, 176 & 3,191 &, 001 \\
THB $<---$ & X3 & $-1,142$ & 1,205 &,- 948 &, 343 \\
THB $<---$ & X2 &, 555 &, 621 &, 893 &, 372 \\
THB $<---$ & X4 &, 134 &, 644 &, 208 &, 836 \\
THB $<---$ & X1 & 1,538 &, 686 & 2,242 &, 025 \\
\hline
\end{tabular}

Tabel Regression Weights menunjukkan nilai estimasi pengaruh satu variabel terhadap variabel lainnya, serta probabilitas yang menunjukkan signifikansi pengaruh dari satu variabel terhadap variabel lainnya. Tabel 4.7 menunjukkan bahwa $X_{1}$ berpengaruh signifikan terhadap $\mathrm{X}_{4}$ dengan $p<0,001 . \mathrm{X}_{2}$ tidak berpengaruh signifikan terhadap $X_{4}$ dengan $p=0,701>0,05 . \mathrm{X}_{3}$ berpengaruh signifikan terhadap $\mathrm{X}_{4}$ dengan $p<0,001$. $\mathrm{X}_{1}$ berpengaruh signifikan terhadap $\mathrm{Y}$ dengan $p=0,025<0,05 . \mathrm{X}_{2}$ tidak berpengaruh signifikan terhadap $\mathrm{Y}$ dengan $p=0,372>$ 0,05. $\quad X_{3}$ tidak berpengaruh signifikan terhadap $\mathrm{Y}$ dengan $p=0,343>0,05$. $\mathrm{X}_{4}$ tidak berpengaruh signifikan terhadap $\mathrm{Y}$ dengan $p=0,836>0,05$.

\section{PEMBAHASAN}

Berdasarkan analisis dengan menggunakan program SPSS, terlihat bahwa rata-rata skor kecemasan belajar siswa adalah 39,12 dan standar deviasi
6,660, variansi sebesar 44,356, dengan skor minimum sebesar 18 dan skor maksimum sebesar 57. Kemudian ada siswa yang berada dalam kategori sangat rendah yaitu 
7 orang, 39 orang yang berada dalam kategori rendah, 105 orang yang berada dalam kategori sedang, 65 orang yang berada dalam kategori tinggi, dan 23 orang lainnya berada dalam kategori sangat tinggi. Sehingga frekuensi terbanyak berada pada kategori sedang dan frekuensi terendah berada pada kategori sangat rendah dari jumlah responden sebanyak 239 orang.

Untuk variabel persepsi siswa tentang keterampilan mengajar guru, ratarata skor persepsi siswa tentang keterampilan mengajar guru adalah 58,70 dan standar deviasi 6,759, dengan skor minimum sebesar 38 dan skor maksimum sebesar 74 dari jumlah responden sebanyak 239 orang. Hal ini berarti bahwa persepsi siswa tentang keterampilan mengajar guru siswa tersebut berada dalam "kategori tinggi" karena berada pada interval $52,25<$ skor $\leq 61,75$. Sedangkan variabel motivasi belajar terlihat bahwa rata-rata skor iklim kelas adalah 59,90 dan standar deviasi 7,524, skor minimum 40 dan skor maksimum 75 yang berarti iklim kelas berada dalam "kategori kondusif" karena berada pada interval $55<$ skor $\leq$ 65.

Berdasarkan analisis dengan menggunakan program SPSS terlihat bahwa tidak ada siswa yang mempunyai skor motivasi belajar yang berada dalam kategori sangat rendah dan 4 orang berada dalam kategori rendah, 64 orang yang memiliki kategori skor motivasi belajar yang sedang, 133 orang yang memiliki kategori skor motivasi belajar yang tinggi sedangkan 38 orang yang berada dalam kategori sangat tinggi. Sedangkan untuk hasil belajar diketahui bahwa 7 siswa memiliki skor belajar matematika yang sangat rendah, 33 siswa memiliki skor hasil belajar matematika rendah, 101 siswa memiliki skor hasil belajar sedang, 94 siswa memiliki skor hasil belajar matematika tergolong tinggi dan 4 siswa memiliki skor hasil belajar matematika yang sangat tinggi. Sehingga dapat disimpulkan bahwa hasil belajar matematika siswa berada pada kategori sedang.

Hasil estimasi parameter (regression weight) menunjukkan nilai estimasi pengaruh satu variabel terhadap variabel lainnya, serta probabilitas yang menunjukkan signifikansi pengaruh dari satu variabel terhadap variabel lainnya. Berdasarkan hasil parameternya terlihat bahwa $X_{1}$ berpengaruh signifikan terhadap $\mathrm{X}_{4}$ dengan $p<0,001 . \mathrm{X}_{2}$ tidak berpengaruh signifikan terhadap $\mathrm{X}_{4}$ dengan $p=0,701>$ 0,05. $X_{3}$ berpengaruh signifikan terhadap $\mathrm{X}_{4}$ dengan $p<0,001 . \quad \mathrm{X}_{1}$ berpengaruh signifikan terhadap Y dengan $p=0,025<$ $0,05 . \mathrm{X}_{2}$ tidak berpengaruh signifikan terhadap $\mathrm{Y}$ dengan $p=0,372>0,05 . \mathrm{X}_{3}$ tidak berpengaruh signifikan terhadap $\mathrm{Y}$ dengan $p=0,343>0,05 . \quad \mathrm{X}_{4}$ tidak berpengaruh signifikan terhadap $\mathrm{Y}$ dengan $p=0,836>0,05$.

Selain probabilitas, pengujian hipotesis juga dapat menggunakan nilai Critical Ratio (CR). Nilai CR merupakan nilai t-value. Nilai C.R. > 2 menunjukkan bahwa hubungan variabel sudah benar. CR $\mathrm{X}_{1}$ terhadap $\mathrm{X}_{4}$ sebesar 3,191>2, menunjukkan bahwa hubungan variabel kecemasan belajar dengan motivasi belajar benar dan sesuai. CR $\mathrm{X}_{3}$ terhadap $\mathrm{X}_{4}$ sebesar 4,066>2, menunjukkan bahwa hubungan variabel persepsi siswa tentang keterampilan mengajar guru terhadap motivasi belajar benar dan sesuai. CR $\mathrm{X}_{1}$ terhadap $\mathrm{Y}$ sebesar 2,242>2, 
menunjukkan bahwa hubungan variabel kecemasan belajar terhadap hasil belajar benar dan sesuai. Sedangkan hubungan variabel-variabel yang lainnya menunjukkan hubungan yang tidak benar

\section{KESIMPULAN}

\subsection{Kesimpulan}

Berdasarkan hasil penelitian pengembangan yang telah dilakukan, dapat ditarik kesimpulan sebagai berikut:

1. Sebagian besar siswa kelas VIII SMP Negeri di Kabupaten Tana Toraja memiliki kecemasan belajar matematika pada kategori sedang dengan skor rata-rata 39,12 dari skor maksimal yang mungkin; persepsi siswa tentang keterampilan mengajar guru pada kategori tinggi dengan skor rata-rata 58,70 dari skor maksimal yang mungkin; iklim kelas pada kategori tinggi dengan skor rata-rata 59,90 dari skor maksimal yang mungkin; motivasi belajar pada kategori tinggi dengan skor rata-rata 59,19 dari skor maksimal yang mungkin; dan hasil belajar matematika pada kategori tinggi dengan skor ratarata 66,67 dari skor maksimal yang mungkin.

2. Kecemasan belajar siswa berpengaruh positif baik secara langsung maupun tidak langsung terhadap hasil belajar matematika. Untuk pengaruh

\subsection{Saran}

Beberapa saran yang berkaitan dengan penelitian ini, sebagai berikut:

1. Hasil penelitian ini dapat dijadikan informasi bagi siswa tentang faktorfaktor yang berpengaruh terhadap hasil belajarnya, sehingga siswa dapat dan tidak sesuai, hal ini dapat dilihat dari nilai CR variabel-variabel tersebut yakni menunjukkan nilai $\mathrm{CR}<2$.

langsung, hasil pengujian data empirik menunjukkan pengaruh yang signifikan ( $\mathrm{r}=0,193)$ dan untuk pengaruh tidak langsung (melalui motivasi belajar) hasil pengujian data empirik menunjukkan pengaruh yang tidak signifikan $(r=0,009)$.

3. Persepsi siswa tentang keterampilan mengajar guru berpengaruh positif dan tidak signifikan $(r=0,0070)$ secara langsung terhadap hasil belajar matematika, namun berpengaru negatif dan tidak signifikan $(r=-0,009)$ secara tidak langsung melalui motivasi belajar siswa.

4. Iklim kelas berpengaruh positif terhadap hasil belajar matematika baik secara langsung maupun tidak langsung melalui motivasi belajar. Untuk pengaruh langsung, hasil pengujian data empirik menunjukkan pengaruh yang signifikan $(r=0,024)$. Begitupula untuk pengaruh tidak langsung (melalui motivasi belajar), hasil pengujian data empirik menunjukkan pengaruh yang tidak signifikan $(\mathrm{r}=0,103)$

mengembangkan faktor-faktor yang ada untuk memaksimalkan belajarnya.

2. Penelitian ini diharapkan dapat menjadi masukan kepada Guru agar dalam suatu pembelajaran bukan hanya kemampuan kognitif siswa yang 
dilihat tetapi juga faktor-faktor psikologi siswa yang dapat mempengaruhi hasil belajar siswa.

3. Bagi peneliti yang berminat untuk melakukan penelitian yang serupa, agar selain meneliti faktor-faktor internal yang mempengaruhi hasil belajar, juga dapat mengembangkan penelitian dengan meneliti faktor eksternal yang mempengaruhi hasil belajar. Peneliti juga dapat membandingkan faktor yang paling besar pengaruhnya terhadap hasil belajar siswa.

\section{DAFTAR PUSTAKA}

Adelman, H S., \& Taylor, L. 1997. Addressing barriers to learning: Beyond school-linkedservices and full service schools. American Journal of Orthopsychiatry, 67, 408421. Diakses tanggal 28 januari 2014.

Atkinson, Rita L. 1993. Pengantar Psikologi. Terjemahan Nurdjannah Taufiq. Jakarta: Erlangga.

Davidoff, Linda L. 1991. Psikologi Suatu Pengantar. Terjemahan oleh Mari Juniati. Jakarta: Erlangga.

Dimyati. \& Mudjiono. 2006. Belajar dan Pembelajaran. Jakarta : Rineka Cipta

Elliot, S.N, Kratochwill, T.R.,Litllefield, J.,Travers, J.F. 1996. Educational Psychology. Second Edition. Madition : Brown dan Benchmark Company.

Hasibuan. 2012. Proses Belajar Mengajar. Bandung : Remaja Rosdakarya

Olaleye, FO. 2011. Teachers Characteristics As Predictor Of Academic Performance Of Students In Secondary Schools In Osun State
-Nigeria. European Journal of Educational Studies 3(3), 505-511. Diakses tanggal 20 Desember 2013.

Purwanto, M. Ngalim. 1988. Prinsipprinsip dan Teknik Evaluasi Pengajaran. Bandung: Remaja Rosdakarya.

Sari, Nila latif. 2013. Pengaruh Metode Mengajar Dan Gaya Kognitif Terhadap Hasil Belajar Matematika Siswa Kelas VIII Mtss Kabupaten Maros. Tesis. Makassar : Program Pasca SarjanaUNM Makassar.

Slameto. 2010. Belajar dan FaktorFaktor yang Mempengaruhinya. Jakarta: Rineka Cipta.

Sudjana, Nana. 2004. Dasar-Dasar Proses Belajar Mengajar. Bandung: Sinar Baru Algesindo Offset.

Sudjana, N. 2012. Penilaian hasil proses belajar mengajar. Jakarta: PT. Remaja Rosdakarya.

Suherman E, Turmudi, Suryadi D, Herman T, Suhendra, prabawanto S, Nurjanah, Rohayati A.2003. Strategi Pembelajaran Matematika 
Kontemporer. Bandung : Universitas Pendidikan Indonesia.

Suparman, S. 2010. Gaya Mengajar yang Menyenangkan Siswa. Yogyakarta : Pinus Book Publisher.

Syah, Muhibbin. 2013. Psikologi Pendidikan. Bandung : Remaja Rosdakarya

Tarmidi. 2006. Iklim Kelas Dan Prestasi Belajar. Program Studi Psikologi. Fakultas kedokteran : Universitas Sumatera Utara
Tim Penyusun Kamus Pusat Pembinaan dan Pengembangan Bahasa. 2007. Kamus Besar Bahasa Indonesia. Jakarta: Balai Pustaka.

Uno, Hamzah. 2012. Orientasi Baru Dalam Psikologi Pembelajaran. Jakarta : Bumi Aksara

Usman, Moch. Uzer . 2010. Menjadi Guru Profesional. Bandung : Remaja Rosdakarya

Walgito, Bimo. 2003. Ps6ikologi Sosial (Suatu Pengantar). Yogyakarta: Andi Offset 